\title{
Reflexões Sobre o Turismo de Base Comunitária e os Povos Indígenas à Luz do Caso Pataxó (Bahia, Brasil)
}

Sandro Campos Neves ${ }^{1}$

\section{Resumo}

Este trabalho discute aspectos do modelo de desenvolvimento brasileiro do turismo de base comunitária (TBC) à luz do caso dos índios Pataxó da aldeia de Coroa Vermelha em Santa Cruz Cabrália, na Bahia. A São retratados os modos como os princípios teóricos básicos do TBC se configuram na realidade empírica Pataxó, buscando repensar aspectos práticos de sua aplicação. A pesquisa etnográfica empreendida entre os Pataxó embasa a reflexão, bem como a análise dos documentos públicos sobre TBC no Brasil. Conclui-se que os princípios básicos do TBC - autogestão comunitária, princípios econômicos solidários e preservação do patrimônio cultural comunitário - se apresentam na realidade Pataxó de maneira bastante diferente daqueles previstos e propostos no modelo. Assim, são propostos elementos para uma avaliação sobre os princípios do TBC e seus modelos de aplicação de modo que venham a se tornar mais próximos das necessidades expressadas pelo estudo em campo de comunidades indígenas e as demais às quais o modelo se aplica. Palavras-chave: Turismo de Base Comunitária; Povo Indígena; Comunidade Tradicional; Modelo de Gestão.

\section{Abstract \\ Reflections about the community-based tourism and indigenous peoples in light of the Pataxó case (Bahia, Brazil)}

This work discusses aspects of the Brazilian development model of community-based tourism (CBT) in light of the case of the Pataxó indigenous people from the village of Coroa Vermelha in the municipality of Santa Cruz Cabrália, state of Bahia (Brazil). It portrays the ways in which the basic theoretical principles of CBT are configured in the Pataxó empirical reality, seeking to rethink practical aspects of its application. The ethnographic research undertaken among the Pataxó is the backdrop for the reflection and the analysis of public documents on CTB in Brazil. It concludes that the basic principles of the CTB - community self-management, solidary economic principles, and preservation of the community cultural heritage - are quite different in the Pataxó reality from those foreseen and proposed in the model. Thus, it proposes elements for an assessment on the principles of CTB and its application models so that they become closer to the needs expressed by the field study of indigenous communities and the others to which the model applies.

Keywords: Community Based Tourism; Indigenous People; Traditional Community; Theoretical Model.

1. Doutor pelo Programa de Pós-Graduação em Antropologia pela Universidade Federal da Bahia (UFBA). Docente do curso de Turismo e do Programa de Pós-Graduação em Turismo na Universidade Federal do Paraná (UFPR), Curitiba, Paraná, Brasil; Em colaboração técnica junto à Universidade Federal de São Carlos (UFSCar), Sorocaba, São Paulo, Brasil. E-mail: sandrocamposneves@yahoo.com.br 


\section{Resumen}

Reflexiones sobre el turismo comunitario y los pueblos indígenas a la luz del caso Pataxó (Bahia, Brasil)

Este trabajo tiene como objetivo discutir los aspectos del modelo de desarrollo brasileño del turismo comunitario (TC) a la luz del caso de los indios Pataxó de la aldea Coroa Vermelha, en Santa Cruz Cabrália, en Bahia (Brasil). Se abordan las formas en que se configuran los principios teóricos básicos del TC en la realidad empírica Pataxó, buscando repensar los aspectos prácticos de su aplicación. La investigación etnográfica llevada a cabo entre los Pataxó fundamenta la reflexión, así como el análisis de documentos públicos sobre TC en Brasil. Se concluye que los principios básicos del TC -autogestión comunitaria, principios económicos solidarios y preservación del patrimonio cultural comunitario- son desde la realidad Pataxó muy distintos a los previstos y propuestos en el modelo. Por lo tanto, se proponen elementos para una evaluación sobre los principios del TC y sus modelos de aplicación para que se acerquen a las necesidades expresadas por el estudio sobre el campo de las comunidades indígenas y las demás a las que se aplica el modelo.

Palabras-clave: Turismo Comunitario; Pueblo Indígena; Comunidad Tradicional; Modelo Teórico.

\section{INTRODUÇÃo}

0 turismo em Terras Indígenas no Brasil tem origens relatadas na bibliografia (Grunewald, 1999; Carvalho, 1977) que remontam ao menos aos anos 1960. Do mesmo período aparecem, em maior número, referências na bibliografia internacional sobre este tipo de turismo (Graburn, 1984; MacCannel, 1992; Nuñez, 1963; Van Den Berghe \& Keyes, 1984; Smith, 1977). No caso brasileiro, o turismo em Terras Indígenas ocorreu até 2016 no que se poderia chamar de informalidade jurídica ou mesmo ilegalidade. A legislação até o período definia que o ingresso em Terras Indígenas só poderia ser feito com a autorização da FUNAI, órgão indigenista oficial, e para fins de pesquisa científica. Apenas a partir da Instrução Normativa número 3 (IN03) da presidência da FUNAI, em 2016, passou a haver algum respaldo legal para a ocorrência da atividade, ainda que não tenham sido devidamente publicizados, até o presente, os respectivos documentos formalizadores da atividade 2 .

Essa situação, entretanto, jamais frustrou a prática de turismo em diversas Terras Indígenas, bem como nos diversos territórios ocupados por povos indígenas, ainda que pendentes de demarcação ou identificação pela FUNAI. Seria possível mesmo afirmar que, a despeito de não haver autorização legal para o mesmo, têm havido reconhecimento governamental para o turismo em Terras Indígenas e preocupações com suas consequências desde muito antes da IN03. Basta, para comprovar tal afirmação, notar que as políticas nacionais de Turismo de Base Comunitária (TBC),

2. A IN03 prevê uma série de documentos formalizadores como o plano de visitação e o formulário individual de ingresso de turistas a ser remetido e aprovado pela FUNAI. Entretanto, os modelos para tais documentos ainda não foram publicizados pela FUNAI e que, ainda que normatizem as práticas da entidade, não servem como modelo a ela externo dada sua falta de conhecimento por eventuais interessados. Em suma, segue sendo um domínio mais propriamente interno à FUNAI do que uma normativa de ampla utilização. 
na maioria dos seus documentos orientadores e normatizadores da atividade, mencionam as Terras Indígenas e seus respectivos povos como objeto.

O que se chama aqui de uma política nacional de Turismo de Base Comunitária foi institucionalizada em 2010, com o edital público de financiamento de projetos do Ministério do Turismo, tendo como objetivo normatizar e fomentar as práticas de turismo nos territórios dos povos tradicionais brasileiros. Essa política visava maximizar os benefícios e minimizar os prejuízos da atividade turística para povos já impactados pelo turismo ou que nele viam alternativas para sua inserção produtiva (Kraychete, 2000). 0 modelo TBC se baseia na premissa de organização comunitária como elemento estruturador e nas práticas associativas e de autogestão do turismo, embora de forma nem sempre sistêmica, dada a assimetria de realidades dos povos envolvidos.

A política foi desenvolvida a partir de edital público que visava financiar projetos nos diversos tipos de comunidades-alvo da política - indígenas, quilombolas, agricultoras, comunidades extrativistas, entre outras. Independentemente do financiamento federal, a partir do edital, as práticas de TBC se tornaram em um tipo de estrutura modelo para o desenvolvimento do turismo envolvendo povos tradicionais. Deste modo, muitas comunidades, influenciadas ou não por idealizadores ligados ao meio universitário, adotaram esse modelo para o desenvolvimento de suas atividades no setor de turismo. Entretanto, o maior ou menor grau de adoção stricto sensu do modelo de TBC, se em algum momento foi objeto de preocupação do governo federal, não foi profundamente discutido. Essa situação resulta no fato de que sua aplicação ocorreu em moldes muito diversos e conduziu ao reconhecimento formal como TBC de vários tipos de atividades e estruturas de desenvolvimento do turismo.

O objetivo deste trabalho é o de analisar aspectos do desenvolvimento turístico em uma comunidade indígena específica, a Pataxó da Terra Indígena Coroa Vermelha, no município de Santa Cruz Cabrália-BA - considerando que as atividades foram desenvolvidas tendo o modelo TBC como base - e avaliar seu grau de aproximação ou afastamento do modelo teórico do TBC. A proposta colocada pelo trabalho é a de apresentar o processo de desenvolvimento da atividade turística, em sua situação contemporânea, em uma perspectiva comparativa com o modelo de TBC, interrogando-se sobre as similitudes e diferenças. Acredita-se que tal discussão é importante para se refletir sobre a adequação do modelo TBC às realidades com as quais anseia atuar, bem como para compreender suas limitações e possibilidades de reformulação.

Para se atingir tal objetivo inicialmente se irá apresentar o modelo de TBC governamental, contrastando-o com os modelos teóricos propostos e, finalmente, compará-los e examiná-los à luz da realidade Pataxó. Espera-se, ao fim do trabalho, demonstrar que existem imperativos organizadores da estrutura social Pataxó que são francamente divergentes e mesmo conflitantes com todos os modelos propostos de TBC ou de Turismo Comunitário. Acredita-se que tal demonstração possa permitir uma reflexão sobre os modelos de Turismo Comunitário e, eventualmente, contribuir para seu aprimoramento e rediscussão no contexto teórico e das políticas públicas de turismo. 


\section{MetOdOLOgIA}

0 presente artigo foi elaborado com base em um tripé metodológico que abrange três tipos de dados como fundamentais para análise. 0 primeiro deles, referente ao material empírico produzido com uma abordagem de campo. Esse material foi produzido a partir de uma metodologia etnográfica sobre o caso do povo Pataxó no município de Santa Cruz Cabrália-BA.

Tal pesquisa tem sido empreendida entre o ano de 2005 e 2019 - com maior intensidade entre os anos de 2009 e 2011 - entre os Pataxó de Coroa Vermelha com vistas à produção de uma tese de doutoramento já concluída. Assim, em que pese o fato de apresentar dados novos, grande parte do material empírico exposto já foi apresentado na referida tese, sendo aqui objeto de novas reflexões à luz de dados recentemente produzidos e do contexto teórico do TBC, que não foi objeto da tese aludida. Considera-se que tal proposta é importante, pois oportuniza uma reflexão que não pôde ser adequadamente empreendida na tese e que importa para um entendimento do turismo entre os Pataxó, bem como para a discussão de modelos de Turismo Comunitário.

0 segundo elemento do tripé metodológico diz respeito à pesquisa documental, na qual se recuperou os editais públicos de TBC - um de financiamento de projetos e um da feira de mostra dos casos apoiados - produzidos pelo governo federal e os submeteu a uma análise de seu conteúdo, buscando evidenciar quais eram os objetivos. Essa análise foi cotejada com a compreensão do contexto sociopolítico que deu causa à elaboração dos editais e do que se está chamando de uma política nacional de TBC. Deste modo, se buscou aclarar os princípios norteadores do modelo TBC no Brasil, a partir de seu reflexo nos documentos públicos, estruturadores de uma almejada política sistemática, a dos editais públicos de financiamento de projetos de TBC.

Finalmente, o terceiro elemento foi realizado a partir de uma proposta de pesquisa bibliográfica a respeito do TBC em Terras Indígenas no Brasil e em alguns artigos considerados mais importantes a respeito da teoria do TBC. Dessa análise foi extraído aquilo que se denomina aqui de os princípios do modelo TBC no Brasil. Para empreender essa proposta foram analisados artigos encontrados nas bases SCielo, Portal de Periódico CAPES (que compreende diversas bases internacionais), Redalyc E Publicações de Turismo. Dessa análise inicial, com os descritores "TBC em Terras Indígenas" e "TBC", foram extraídos os artigos que enfatizavam em seu texto os princípios norteadores da prática do TBC, de onde se obteve a estrutura teórica que aqui se considera como base para análise da documentação e do material empírico. Em relação à pesquisa bibliográfica, foi empreendida a partir de uma proposta de revisão narrativa (Cordeiro, 2007), na qual não se busca uma análise estatística como na bibliometria, mas uma análise qualitativa.

Obviamente, tal proposta, como aborda Cordeiro (Op. cit), significa se submeter à possibilidade de produção de vieses em busca de aprofundamento em conteúdos específicos. Deste modo, se poderia dizer que, no caso da revisão narrativa, o problema de pesquisa em questão não se encontra explícito nos dados numéricos a respeito dos temas pesquisados, mas na explicitação própria de determinados aspectos da teoria que se busca analisar. Essa escolha foi feita em função da percepção de que, em muitos dos artigos encontrados na busca, os princípios do TBC buscados apareciam como pressupostos ou subentendidos, não sendo 
mencionados explicitamente. Deste modo, se fosse feita a opção de análise de todo o material seria necessária a dedução dos princípios a partir das análises de caso, procedimento que, acreditou-se, resultaria em ainda mais vieses.

\section{OS PRINCÍPIOS TEÓRICOS DO MODELO TBC}

O turismo de base comunitária, como modelo teórico de desenvolvimento turístico, nasce no contexto de um conjunto de preocupações com a sustentabilidade do modo de produção capitalista vigente na maior parte das economias nacionais do mundo. Esse movimento pode ser corretamente situado como tendo seu ápice no contexto que levou à realização da "ECO-92" e dos objetivos da sustentabilidade por parte das Nações Unidas. Tais preocupações têm, portanto, suas origens na inquietação manifestada no ambiente acadêmico por autores como Ignacy Sachs (1992), Wolfgang Sachs (1992) e Enrique Leff (2001) em relação às consequências ecológicas, sociais e econômicas do modelo de desenvolvimento econômico que vinha sendo aplicado no mundo inteiro e que se aprofunda, no contexto latinoamericano de forma especial, com a hegemonia do denominado "consenso de Washington".

Na esteira destas preocupações surgem, em especial nos chamados países em desenvolvimento, a proposição de alternativas econômicas que tomam como agenda prioritária o combate às desigualdades econômicas e sociais e aos prejuízos ambientais do processo de desenvolvimento econômico no mundo. Essas proposições resultam na formulação de princípios para a estruturação de modelos econômicos de desenvolvimento. Tomamos aqui, como um dos resultados mais importantes desse processo no caso brasileiro, a proposição dos princípios da economia solidária (Singer, 2002), - por sua vez herdeiros das análises sobre cooperativismo e associativismo empreendidas desde o início da escola cepalina - que formam a base do modelo TBC. Maldonado, um dos teóricos seminais do TBC, considera que:

Por turismo comunitário entende-se toda forma de organização empresarial sustentada na propriedade e na autogestão sustentável dos recursos patrimoniais comunitários, de acordo com as práticas de cooperação e equidade no trabalho e na distribuição dos benefícios gerados pela prestação dos serviços turísticos. A característica distinta do turismo comunitário é sua dimensão humana e cultural, vale dizer antropológica, com objetivo de incentivar o diálogo entre iguais e encontros interculturais de qualidade com nossos visitantes, na perspectiva de conhecer e aprender com seus respectivos modos de vida. (2007 p.09)

No contexto teórico e acadêmico, os modelos de TBC são bastante diversos entre si e apontam para diferentes questões tendo em vista o contexto em que foram produzidos. Majoritariamente os estudos estão situados em áreas rurais dos países em que ocorrem. Autores como Maldonado (2007); Skewes, J. C., Zuñiga, C. H., \& Vera, M. P. (2015); Bartholo, Bursztyn, Fratucci \& Assad (2016) e Ruiz, Hernández, Coca, Cantero \& Campo (2008) que se referem de maneira mais geral ao modelo TBC e seus princípios apontam suas bases como estando vinculadas a questões como justiça social, preservação ambiental, protagonismo político das comunidades e desenvolvimento econômico e social das mesmas. Por outro lado, autores que 
estudaram mais diretamente o TBC entre povos indígenas como Morales Morgado (2006), Morales, Arias \& Bizuet (2014) e Dachary, A. C. (2009) apontam para questões como valorização da tradição, fortalecimento da identidade cultural e organização política das comunidades como norteadores do modelo.

Chaves, Castro e Pinto (2013 p. 216) sumarizam os princípios norteadores do TBC, a partir de análise detida da produção acadêmica, de acordo com as seguintes subdivisões: Autogestão, Protagonismo Social, Reafirmação Cultural e Minimização dos Impactos Ambientais. Dentro de cada um destes princípios identificam idéias-chave que correspondem aos seguintes conjuntos. Autogestão Cooperativismo; Benefícios Coletivos; Associativismo; Desenvolvimento de Arranjos Produtivos; Economia Solidária. Fabrino; Nascimento e Costa (2016 p. 176), por sua vez, estabelecem os princípios de Dominialidade, Organização comunitária, Democratização de oportunidades e repartição de benefícios, Integração econômica, Interculturalidade e Qualidade ambiental.

Embora partam de diferentes perspectivas, acredita-se que todo esse conjunto de autores concorda, em seus textos, em relação a determinados princípios do TBC e em relação às questões estruturais, sociais e econômicas do modelo. Se poderia, tentativamente, denominar tais questões como autogestão comunitária, princípios econômicos solidários e preservação do patrimônio cultural das comunidades. Por autogestão comunitária se pressupõe um entendimento não apenas da tomada autônoma de decisões, mas sua horizontalização e norteamento para princípios democráticos paritários. Por princípios econômicos solidários entende-se o conjunto de práticas ligadas à economia solidária e aos princípios de comércio justo e justiça social. Finalmente, por preservação do patrimônio cultural se compreende idéias como manutenção de tradições, fortalecimento da cultura e identidade das comunidades.

A realização dessa síntese, embora tentativa e algo precária é necessária para a proposta de análise do modelo brasileiro de TBC que se pretende nesse trabalho. A partir destas três dimensões é que se fará a análise do caso Pataxó, evocando conceitos sugeridos pelos diversos grupos de autores.

\section{O modelo institucional de TBC no Brasil}

Na esteira destas preocupações acadêmicas e científicas, produzidas com a explicitação das características dos modelos extraída da experiência empírica, o Ministério do Turismo, seguindo a orientação geral do governo federal naquele momento, e em consonância com os objetivos do Plano Nacional de Turismo 2007-2010 - denominado “Uma viagem de inclusão" - propõe, em 2010, no edital de fomento a projetos de TBC a seguinte definição:

O turismo de base comunitária, turismo comunitário, solidário, de conservação, entre outras denominações, possui elementos comuns a tais iniciativas e busca a construção de um modelo alternativo de desenvolvimento turístico, baseado na autogestão, no associativismo/cooperativismo, na valorização da cultura local e, principalmente, no protagonismo das comunidades locais, visando à apropriação por parte destas dos benefícios advindos do desenvolvimento da atividade turística. (Edital TBC, 2010) 
O conjunto de definições que se adota nas políticas nacionais de turismo, embora muito diversas, resultante das diferentes definições cunhadas no campo acadêmico é situada pelo próprio documento como tendo alguns pontos em comum. 0 modelo se basearia, na visão do Mtur, nos seguintes princípios:

[...] autogestão; associativismo e cooperativismo; democratização de oportunidades e benefícios; centralidade da colaboração, parceria e participação; valorização da cultura local e, principalmente; protagonismo das comunidades locais na gestão da atividade e/ou na oferta de bens e serviços turísticos, visando à apropriação por parte destas dos benefícios advindos do desenvolvimento da atividade turística. (Edital TBC, 2010)

Consoante com os princípios supramencionados o documento estabelece os seguintes objetivos:

- Fomentar as iniciativas existentes organizadas e/ou identificadas como de Turismo de Base Comunitária (TBC);

- Apoiar projetos de TBC, para o fortalecimento de roteiros segmentados, com foco no território para o desenvolvimento local e inclusão social, qualificação, certificação, apoio à produção associada ao turismo e desenvolvimento local/inclusão social.(Edital TBC, 2010)

As linhas de financiamento foram pensadas para atender ao conjunto de formulações de princípios e objetivos nos seguintes termos:

Linha temática 1: Apoio à produção associada ao turismo; Linha temática 2: Apoio à qualificação profissional; Linha temática 3: Apoio ao planejamento estratégico e organização comunitária; Linha temática 4: Apoio à promoção e à comercialização; Linha temática 5: Apoio às ações de fomento às práticas de economia solidária. (Edital TBC, 2010)

A partir desse conjunto de diretivas, a política do Mtur tinha como expectativa o alcance dos seguintes resultados:

- Maior participação das comunidades locais nos benefícios advindos da atividade turística. Comunidades locais qualificadas para a gestão da atividade turística. Geração de trabalho e renda ligada a iniciativas de TBC.• Articulação de iniciativas do segmento "Turismo de Base Comunitária" em rede.• Articulação e parcerias entre as esferas públicas e privadas responsáveis pela gestão da atividade turística em destinos em que o TBC se desenvolve.(Edital TBC 2010)

Nesses termos, se pode identificar significativa consonância entre os modelos teóricos e o modelo governamental. Em realidade, se for analisado seu processo de produção textual, parte importante dos acadêmicos envolvidos na formulação do modelo teórico participaram da elaboração do edital. Não obstante, existiram determinados aspectos da implantação do modelo que foram diretamente coordenados pelo Mtur e que escaparam a qualquer ingerência mais direta do contexto acadêmico. De toda forma, o que se pretende analisar aqui são aspectos 
da realidade empírica de uma comunidade, não financiada pelo edital, mas que pautou seu modelo de desenvolvimento turístico no que se está chamando aqui de modelo TBC. Ainda assim, pretende-se demonstrar haver similitudes e diferenças no modelo Pataxó e o que se deseja é, afinal, realizar uma discussão concertada entre esses três domínios - o teórico, o institucional e o empírico - de modo a aprofundar a compreensão da aplicação do modelo TBC, em especial em seus princípios, em uma comunidade que seria objeto de seu desenvolvimento, dados seus balizadores teóricos e institucionais.

Deste modo, tais definições apontam para alguns aspectos importantes a serem analisados como proposta. 0 modelo de TBC se propõe a trabalhar a partir da questão da desigualdade grassante nos diversos setores econômicos, em especial nos chamados países em desenvolvimento - na América do Sul e África, sobretudo. Para isso baseia-se em perspectivas tais como a da economia solidária, que por sua vez se baseia na lógica do comércio justo. Também se orienta pela lógica do associativismo e dos princípios de autogestão e participação comunitária, bem como da valorização da cultura local e do protagonismo das comunidades. Entretanto, os editais e grande parte das discussões acadêmicas se preocuparam pouco com duas questões de fundo - os instrumentos de gestão e o levantamento quantitativo dos resultados econômicos da política. Essas questões de fundo, que poderiam ter sido parte de instrumentos posteriores a serem criados pelo Mtur, deixaram de ser tratadas em função, de um lado da priorização dos megaeventos Copa do Mundo e Olimpíadas na agenda pública do governo federal, e de outro da interrupção abrupta do governo após o fim da Copa do $\mathrm{Mundo}^{3}$, que deu lugar a outras lógicas de pensamento sobre economia e desenvolvimento.

0 objetivo deste trabalho, como mencionado é comparar os princípios e o modelo do TBC como política pública no Brasil com uma situação empírica específica, a dos Pataxó de Coroa Vermelha. 0 caso analisado foi constituído com base no modelo de TBC, mas sua execução apresenta similitudes e diferenças dignas de nota. Assim, no seguimento serão apresentados em linhas gerais os fundamentos do modelo Pataxó de desenvolvimento do turismo a partir dos dados de campo e espera-se que, após tal análise, seja possível realizar uma reflexão sobre o TBC à luz da experiência Pataxó para retomar questões ainda sobre o formato do modelo.

\section{O tURismo Pataxó - história e características do MODELO}

0 desenvolvimento do turismo entre os Pataxó se inicia com o processo de construção e consolidação do próprio destino Porto Seguro-BA, vizinho à aldeia de Coroa Vermelha. Os Pataxó, como demonstra a literatura (Grunewald, 1999; Carvalho, 1977), vieram à região da praia de Coroa Vermelha novamente - uma vez que já ocuparam aquela faixa de território no período pré-cabralino em disputa e coabitação com os Tupi da costa - nos anos 1960. Foram levados à região em função de sua expulsão pelo IBDF da região de Monte Pascoal, onde foi criado um Parque Nacional, e também da Aldeia de Barra Velha, no município de

3. Aqui nos referimos ao Impeachment da presidente Dilma Roussef ocorrido em 2016 e caracterizado, de modo adequado, em nossa concepção, como "o golpe de 2016", que deu lugar ao retorno da vertente neoliberal de gestão econômica. 
Caraíva-BA, de onde saíram em busca de melhores condições de vida. Com a criação da BR 367 começam a chegar à região grupos crescentes de turistas desde os anos 1970. Os Pataxó buscaram a região de Coroa Vermelha e ali se estabeleceram nos anos 1960 em função da posição de entreposto exercida pela região, o que lhes proporcionou estabelecerem-se ali como comerciantes. Essa posição foi reforçada com a chegada dos primeiros fluxos massivos de turistas, com quem os Pataxó também passaram a comerciar.

Nos anos 1990, os Pataxó conseguem a demarcação da Terra Indígena de Coroa Vermelha, que inclui a região de praia e uma porção de Mata Atlântica, denominada gleba B da demarcação da TI Coroa Vermelha. Nessa área começaram a desenvolver o projeto Jaqueira de Ecoturismo. Naquele momento, apoiados por diversos parceiros, os Pataxó articularam o interesse na ocupação da área de mata e o interesse no desenvolvimento de um projeto de turismo com as preocupações ambientais, pertinentes à agenda da época, o que se evidencia na escolha do nome de Projeto de Ecoturismo da Jaqueira. Naquela área os Pataxó estabeleceram um processo de desenvolvimento turístico que estava associado àquilo que já se desenvolvia na região de praia, com o comércio de artesanato aos turistas. Entretanto, na visão dos Pataxó a área de mata deveria servir a duas preocupações fundamentais; à própria preservação da mata como elemento importante ambientalmente e para a socialidade indígena e à preservação e exercício de tradições espirituais e culturais vinculados à relação com a floresta. Assim, o projeto da Jaqueira foi se constituindo e se estabelecendo, desde os anos 1990, em consonância com preocupações que também estão na origem do modelo de TBC, as preocupações ambientais, as culturais e as econômicas, que dariam causa à manutenção de seu modo de vida.

\section{AUTOGESTÃo COMUNITÁRIA e PRINCÍPIOS ECONÔMICOS SOLIDÁRIOS}

O modelo TBC se pautou pelas considerações anteriormente explicitadas e pôde ser sumarizado como tendo entre suas características mais importantes os elementos da autogestão comunitária, princípios econômicos solidários e preservação do patrimônio cultural das comunidades. 0 objetivo deste texto, no que segue é observar estes três aspectos no modelo de TBC desenvolvido entre os Pataxó de Coroa Vermelha, analisando semelhanças e diferenças com o modelo teórico. Tal análise leva em consideração que o modelo Pataxó angariou relativo sucesso, de tal modo se busca, no contraste da teoria com a experiência empírica, lançar luzes sobre algumas contradições objetivando compreender suas implicações para a teoria do TBC.

As diferenças com as bases teóricas do modelo de TBC já podiam ser observadas em aspectos do próprio processo de constituição da Terra Indígena e de apropriação da área de mata em que se desenvolveu o projeto Jaqueira de Ecoturismo. Se, por um lado, o modelo de TBC prega o associativismo e a participação coletiva e paritária, o modelo de turismo dos Pataxó tinha que se haver com a tradição de organização política daquele povo, de muitos modos estranha à lógica associativa e paritária. Para iniciar essa exposição seria importante dizer que o processo de apropriação da área de mata foi protagonizado e hegemonizado por um único 
grupo familiar, composto de três irmãs e suas respectivas famílias nucleares e extensas. Esse grupo familiar teria sido o único que, no momento da demarcação, manifestou interesse e tomou todas as providências para a ocupação da área de mata, o que justificou inicialmente sua ocupação da área. Entretanto, a continuidade da ocupação e sua hegemonia tem relação com outros aspectos da tradição.

Diversas vezes, durante a pesquisa de campo, os Pataxó relataram o fato de que desde a aldeia de Barra Velha - onde foram agrupados no século XIX pelo governo central junto com os demais índios encontrados na costa - os caciques Pataxó pertenceram sempre a três grupos familiares. As irmãs que hegemonizam até a atualidade a ocupação da área pertencem a um destes grupos. Sua dominância na ocupação da área sempre passou pela determinação de quais índios poderiam ou não participar do projeto Jaqueira e, ainda que tal escolha tenha sido pactuada de diversos modos com outros grupos familiares, o fato é que o comando sempre pertenceu às três irmãs e seu respectivo grupo familiar.

Este fato, por si só permite observar um aspecto da teoria que seria muito importante. Para a maior parte dos autores citados e utilizados como referenciais fundamentais para a construção do modelo TBC, os objetivos de justiça social, desenvolvimento comunitário e preservação ambiental, para ser alcançados, passavam decisivamente pela autogestão comunitária em moldes paritários e associativos. Entretanto, o modelo Pataxó teve algumas diferenças importantes com esses princípios sem deixar de ter relativo sucesso. Ainda que se possam apontar problemas no que diz respeito à distribuição direta dos benefícios do turismo e mesmo de minoração da desigualdade social, o fato é que o modelo desenvolvido em Coroa Vermelha alcança sucesso, inclusive - e talvez principalmente - nestes aspectos.

Observado desse modo, o modelo Pataxó de Turismo Comunitário se distancia do modelo ideal do TBC em favor de uma lógica local de distribuição de poder e representatividade. Como mencionado, existem diversos modos específicos de lidar com o problema de concentração de poder político para que ele se reflita menos na concentração econômica. Além das pactuações com outros grupos familiares para a participação no projeto de turismo existem também os mecanismos de solidariedade.

Importa esclarecer que a diferença de acesso à participação no Projeto de Ecoturismo da Jaqueira jamais foi pensado pelos Pataxó como um processo de concentração de poder de forma a controlar os fluxos de capital. Ainda que, certamente, acabe tendo tais efeitos e estes sejam percebidos pelos índios de forma clara em termos causais, para os Pataxó sempre se tratou do modo tradicional de exercício de liderança política. Contudo, face tanto à necessidade de sobrevivência quanto à penetração de idéias ocidentais na comunidade, também houve desde que se têm notícias e, sobretudo, naquilo que pôde ser observado em pesquisa de campo, mecanismos de solidariedade que compensavam essa concentração de poder político que resulta em concentração econômica.

Clastres (2003) já havia demonstrado que a estrutura de chefia entre os povos indígenas da América do Sul era concentradora de representatividade, mas não necessariamente de poder. Para o autor a chefia indígena, antes que concentradora de poder, concentrava representatividade - e eventualmente alguma vantagem social - à custa de uma prática de constante doação a enfraquecer e, na visão do autor, solapar completamente a perspectiva de um poder centralizado. Isto é, como forma de evitar justamente que a concentração de representatividade política se 
tornasse poder a comunidade exigia da liderança política uma postura de completa doação e abnegação. Todos os bens do líder podiam, na narrativa do autor, ser reivindicados pela comunidade, assim como suas conquistas. Esse seria o modo, na interpretação de Clastres (Op. Cit.), de se contrapor à perspectiva de nascimento de um poder central. Assim, as tais sociedades contra o Estado na visão de Clastres (Op. Cit.) se formavam a partir da negação do poder político.

Para os Pataxó o caso, evidentemente, é substancialmente diferente. A preocupação com a concentração do poder político passa necessariamente pela evitação da concentração do poder econômico, isto é, trata-se de cuidar que a liderança política não implique em concentração de recursos e excessiva desigualdade. A forma que foi encontrada sempre para que isso fosse conseguido foi a da solidariedade social de recorte étnico, isto é, a preocupação com a "causa" indígena. Deste modo, em primeiro lugar, todas as conquistas da liderança política - fossem econômicas ou de qualquer outro tipo - deveram sempre ser coletivizadas de algum modo. No caso do projeto de turismo as formas de coletivizar passam pela solidariedade entre grupos familiares no que se refere à subsistência, bem como na busca de recursos a serem coletivizados para a sobrevivência social, tais como a escola indígena. Assim, as famílias que hegemonizam a ocupação da Reserva Jaqueira precisam constantemente colaborar com a subsistência de diversos grupos familiares a eles associados bem como coletivizar conquistas advindas do ganho econômico. Nesse caso, um dos modos de se proceder tal feito foi a construção de mais uma escola indígena na Reserva Jaqueira, para além da que já existe em Coroa Vermelha, para atender às crianças da comunidade de Coroa Vermelha.

0 processo de solidariedade social não se dá apenas em quesitos econômicos ou na coletivização de recursos importantes, mas também na coletivização da gestão do turismo através de instrumentos políticos. Essa idéia se materializa na gestão do chamado Parque Indígena. Todo o complexo turístico Pataxó que inclui as lojas de artesanato na praia de Coroa Vermelha, o estacionamento a ela anexo, o Museu Indígena da Coroa Vermelha e o próprio Projeto Jaqueira de Ecoturismo, este último em menor escala, constituem o que os índios chamam de o Parque Indígena. A gestão destes espaços foi estabelecida como uma instituição política separada, ainda que subordinada à gestão do cacique. Embora seu poder de influência seja menor exatamente no Projeto Jaqueira de Ecoturismo, ainda assim ela é uma forma de coletivizar poder de decisão. A gestão do Parque Indígena, portanto, se responsabiliza pela manutenção dos espaços e pela administração dos conflitos. Durante o período de pesquisa de campo essa gestão foi exercida por um único índio, o 'Loro', mas sempre se tratou de uma espécie de associação indígena. Já era um fato digno de nota que a administração do turismo escapasse do controle direto do cacique, mais importante ainda é o fato de sua coletivização, ainda que formalmente exista a figura do administrador. A gestão do Parque Indígena sempre foi, durante o período de pesquisa de campo, um assunto coletivo e, ainda que jamais existisse um conselho, colegiado ou outro órgão coletivizador formal, todos os assuntos de importância são comumente discutidos de forma coletiva entre os interessados.

O interesse, aliás, é uma convenção bastante importante para os Pataxó como instrumento coletivizador de poder e construtor de autoridade política da liderança indígena. Já foi demonstrado em outra parte (Neves, 2012) que, para os Pataxó, um elemento tão importante quanto o pertencimento às famílias 
tradicionalmente detentoras da liderança indígena é o interesse e participação na política. Os jovens das famílias politicamente preponderantes são constantemente instados a participar das ações políticas do movimento indígena e tomar parte nas decisões coletivas. Embora essa pressão se refira, de algum modo, a todos os Pataxó, ela é um peso significativo para os jovens candidatos a futura liderança no movimento indígena. Desse modo, o interesse e a participação direta são critérios constantemente acionados para legitimar liderança política, decisões de administração de conflito e direito maior ou menor à participação e usufruto de benefícios de atividades econômicas, entre elas o turismo. Aos "não-interessados" resta a ação individual e a sujeição à solidariedade étnica como instrumentos de obtenção de vantagens econômicas e subsistência.

Através dessa breve exposição se buscou demonstrar de que modos o modelo de TBC Pataxó se aproxima e se afasta do modelo institucional e nacional de TBC. Por intermédio de instituições eivadas de uma lógica especificamente Pataxó se estabelecem mecanismos de controle informais ou pré-formais da concentração de poder e recursos econômicos. A escolha destes mecanismos laterais se orientou pelo fato de que formalmente não havia possibilidade ou interesse de desconstituir e refazer as estruturas de poder e representação política manifestadas pela gestão do cacique e a instituição da liderança e chefia entre os Pataxó.

\section{Preservação do patrimônio cultural das comunidades}

Com relação ao último aspecto da tríade que se considerou aqui como fundamental para o TBC - a preservação do patrimônio cultural da comunidade - o caso, entre os Pataxó, também apresenta aspectos dignos de nota. A suposição da teoria seria de que o modelo de TBC, ao valorizar a ação coletiva e a solidariedade econômica, resultaria, de modo mais ou menos mecânico, na preservação do patrimônio cultural das comunidades. Assim, a suposição é a de que sendo a preservação do patrimônio um importante elemento de atratividade turística e, portanto, de subsistência econômica, a ação coletiva colocada em marcha naturalmente se interessaria por ela.

Contudo, nesse ponto também o modelo Pataxó ocorreu de modos diferenciados. Em se tratando de uma comunidade indígena do Nordeste brasileiro já existe ampla bibliografia (Barreto Filho, 2004; Oliveira, 2004) que relata os chamados processos de ressurgimento étnico e as retomadas e reelaborações da tradição neste contexto. 0 caso Pataxó não se afasta dessa realidade regional. Em função de seu histórico prolongado de colonização e da intensa influência e proximidade física das comunidades não-indígenas, os índios do Nordeste e, de modo mais amplo, os índios do Leste brasileiro, lidaram constantemente como a necessidade de rearticular e reelaborar suas tradições face ao colonialismo constante que Oliveira (Op.Cit.) chamou de situação colonial - e as pressões da sociedade envolvente. Desse modo, aquilo a que se chamou de reinvenção cultural, invenção das tradições ou reelaboração cultural indígena foi uma marca constante do modelo Pataxó de TBC. Isto significa dizer que, antes de uma preservação linear de patrimônio cultural "detido" por uma comunidade, a situação dos índios do Nordeste foi de necessidade de reelaboração constante, ainda que consequente, de suas tradições, face às vicissitudes do contato com os brancos. 
Assim, no caso do TBC Pataxó em Coroa Vermelha foi necessário instituir, criar e reinventar formas sociais e coletivas de lidar com o turismo. Tais formas, se de algum modo se afastam da tradição Pataxó, tem como ela relações de sistematicidade e reflexão constantes. 0 chamado patrimônio cultural da comunidade, que o TBC almeja preservar, para os Pataxó, vinha sofrendo processos sucessivos de reelaboração ao menos desde o século XIX, com seu aldeamento em Barra Velha.

0 relato do conjunto destas modificações já foi objeto da tese de doutoramento e de outros textos, de modo que interessa reter para essa discussão apenas um aspecto fundamental que lida com o conceito mesmo de tradição. Aquilo que o senso comum denominaria de tradição Pataxó, imaginando a como imemorial e imutável, obviamente foi brutalmente reformulado no decurso dos séculos desde a colonização e, sobretudo, a partir do século XIX, com o aldeamento e do século XX, com a aceleração do processo de globalização e o correspondente aumento massivo das trocas interculturais. Nesse contexto, os processos de mudança cultural a que os Pataxó foram submetidos foram drásticos se comparados à sua realidade do século XVI, da qual se tem parcos, mas decisivos relatos. Seu artesanato, seu modo de vida, suas concepções cosmológicas e todas as manifestações culturais foram dramaticamente alteradas, reconfiguradas, esquecidas, forçosamente abandonadas e finalmente reinventadas. Desse modo, se poderia considerar, de acordo com determinadas concepções de tradição, que qualquer objetivo de preservação cultural estaria inevitavelmente frustrado.

Ainda que existam considerações nesse sentido na teoria, o que se pretende demonstrar aqui é algo no sentido oposto. Quando se alude às mudanças na tradição ritual ou na prática artesanal Pataxó, sobretudo à luz da atividade turística, se pretende discutir as relações entre sistematicidade cultural e preservação de manifestações. Toda a vida ritual e as práticas artesanais Pataxó foram reconfiguradas pelo processo de colonização e, uma vez mais, pelo advento do turismo. Assim, se pode, sem sombra de dúvida, dizer que há um artesanato Pataxó e uma tradição ritual Pataxó pré e pós colonização, bem como pré e pós inserção da atividade turística. Os Pataxó, de fato, reconfiguraram sua tradição artesanal e a ela agregaram plasticidade e atratividade propriamente turísticas, bem como o fizeram no contexto das vicissitudes da colonização. Entretanto, a visão que se advoga aqui é a de que tais reconfigurações obedeceram a anseios próprios, conectados com a tradição, tanto quanto a imposições colonialistas.

No que se refere ao artesanato há imensa discussão a respeito de sua retomada ou recriação após os anos 1960 à luz do turismo. Tais discussões, inclusive, refletem sobre a possibilidade de uma criação do artesanato Pataxó para o turismo e passam pela intervenção de instituições nacionais como o SEBRAE, que ofereceu aos índios oficinas de produção artesanal. Entretanto, para os Pataxó, é importante lembrar que toda sua história pós-colonial foi estruturada por trocas culturais e empréstimos de parte a parte com os brancos que colonizaram o Brasil. Assim, as modificações nas práticas artesanais face ao turismo são encaradas com relativa serenidade, uma vez que se compreende que a prática artesanal, desde a colonização, deixou para sempre de ser apenas utilitária e se tornou instrumento de comunicação intersocietária. Deste modo, não haveria qualquer contradição em refazer os modos de produção artesanal em virtude do turismo, sendo este atualmente um instrumento privilegiado das comunicações e trocas interculturais. 
O mesmo se pode dizer a respeito de tradição ritual e suas conexões cosmológicas. Ainda que instrumentos de uma vivência cultural supostamente mais interna, tais práticas sempre foram também veículos de expressão de fronteiras étnicas. Isto significa dizer que a prática dos rituais sempre foi uma maneira de se singularizar como indígenas e se diferenciar dos brancos. Assim, sua eventual nova plasticidade turística nada teria de extraordinária, na medida em que se a situação de fronteira étnica (Barth, 1998) se modifica com o turismo - e tal não pode ser negado - nada mais "natural" que o veículo de sua expressão também mude. Muito do que se associa à invenção de tradições rituais Pataxó para o turismo, tem que ser discutida, na realidade, em sua conexão com o exercício da reflexão sobre a fronteira étnica e o modo de expressá-la e torná-la pública. Não resta dúvida que tradições foram reconfiguradas e que houve um retorno retórico a tradições rituais abandonadas ${ }^{4}$. Entretanto, a reflexão necessária sobre tais retornos tem que se haver com o fato de que a colonização e o turismo impuseram a necessidade de revisar as fronteiras étnicas e, de algum modo, performar essa fronteira de maneira ritualística e realizar a exposição desses rituais como forma de comunicar a diferença.

Finalmente, o que deseja demonstrar aqui a respeito das modificações realizadas na tradição Pataxó face às imposições da atividade turística tem relação com a sistematicidade presente na ideia de tradição. Adotando uma formulação de tradição como a de Toren (1988) se deduz aqui que tradição seja, antes que uma forma de replicar manifestações objetivas, um modo subjetivo de entabular uma maneira local de fazer as coisas. Tal modo, sobretudo em seus processos de reconfiguração, se traduziria fundamentalmente em manter algum nexo subjetivo com a tradição como conjunto de ideias, antes que a manutenção de práticas e técnicas objetivas de execução de danças, artesanato ou rituais.

Assim, tendo em vista o objetivo da preservação da tradição se visualiza importante diferença de concepção. Se os modelos teórico e institucional de TBC abordam a tradição de um modo objetivo, como manutenção de práticas e saberes supostos como imemoriais, o modo Pataxó de preservar seu patrimônio cultural se articula de outras maneiras. Assim, para os Pataxó, a preservação do patrimônio tem relação com a manutenção dos sentidos subjetivos das práticas, atualizados para a situação contextual contemporânea. Tal concepção pode significar, inclusive, a alteração radical da técnica e a adoção de novos modos de fazer, desde que esses preservem o sentido mesmo de cada tipo de tradição e de seu conjunto, qual seja, fundamentalmente como marcador da diferença ou traço diacrítico de indianidade, neste caso.

4. São dignos de nota aqui o retorno a tradições rituais que sequer seriam próprias, no sentido purista do termo, como a dança do Toré, ou a retomada de tradições sobre as quais as gerações atuais, no máximo, haviam ouvido falar como o casamento ritual no Aragwaksã - um tipo de casamento precedido por práticas rituais como o carregamento de toras de madeiras correspondentes ao peso da noiva como demonstração da capacidade do futuro marido de suportar carregá-la em momento de extrema urgência e necessidade. 


\section{Conclusões}

Ao longo deste trabalho se buscou realizar uma comparação entre aquilo que se chamou de modelos teórico e institucional de TBC com uma situação empírica estudada através de pesquisa etnográfica, a realidade Pataxó da aldeia de Coroa Vermelha em Santa Cruz Cabrália-BA. O objetivo foi demonstrar diferenças e semelhanças entre os modelos, buscando estabelecer um diálogo que visa o aprimoramento do modelo de TBC para aplicação futura em políticas de turismo. Assim, em primeiro lugar se realizou uma revisão da literatura que inspirou a construção do modelo institucional de TBC, em seguida se buscou realizar uma análise dos documentos nacionais sobre TBC e extrair seus pressupostos fundamentais e, finalmente, comparar com a realidade empírica Pataxó.

Das análises preliminares, documental e bibliográfica, se extraiu três princípios ordenadores básicos - o da autogestão comunitária, o dos princípios econômicos solidários e o da preservação do patrimônio cultural comunitário. A partir destes princípios se realizou a análise da situação Pataxó buscando identificar as diferenças contextuais e conceituais entre modelos e realidade empírica.

Como demonstrado, o modelo TBC responde, em sua formulação teórica e bases de aplicação, a uma preocupação com justiça social, em sentido amplo, e às demandas de preservação e sustentabilidade ambiental, bem como à necessidade de proposição de um modelo alternativo de desenvolvimento econômico para o mundo. Entretanto, ainda que consoante com as demandas do modelo TBC, o modelo Pataxó esteve sempre vinculado a demandas mais propriamente indígenas e que estão muito mais conectadas à questão da sobrevivência e resistência cultural e, portanto, à sobrevivência física, do que à proposição de um modelo alternativo de desenvolvimento. Isso significa dizer que, na medida em que tenta se haver com sua própria realidade, o modelo Pataxó de Turismo Comunitário é bastante mais fluido e flexível no que diz respeito às condicionantes do TBC. Deste modo, não há, por exemplo, uma inflexão em direção a um modelo paritário e associativo de turismo, calcado na proposição teórica de uma alternativa de desenvolvimento. Isto é, o modelo TBC, neste quesito, não dialoga com as práticas indígenas e, por consequência, não é por elas acatado. Os resultados práticos dessa situação estão no fato de que para os Pataxó a sobrevivência individual e coletiva, que pode resultar numa adaptação às regras do jogo, são mais importantes que qualquer consideração teórica ou conceitual sobre igualdade, paridade e justiça social nos termos ocidentais. Tal afirmação não se confunde com a idéia de que esses preceitos não estão em tela no modelo Pataxó, mas com o fato de que eles são pensados de outro modo e que a sobrevivência coletiva e a subsistência de um modo de vida indígena antecedem quaisquer outras ponderações.

Deste modo, um balanço final da análise do caso Pataxó permite entrever a necessidade de nova reflexão e reelaboração dos princípios do TBC face à realidade das comunidades. A necessidade imperiosa de reflexão e mudança se relaciona com potenciais consequências de desestruturação do modelo, de um lado, ou de desorganização das comunidades, de outro. Quaisquer das opções são contrárias aos interesses dos formuladores dos modelos teóricos e institucionais do TBC e, obviamente, a reflexão importa diretamente a eles, mas também se relaciona com uma discussão que envolve grandes conjuntos populacionais da sociedade brasileira. 
Ademais, a análise empreendida deseja deixar perceptível o fato de que a rediscussão dos modelos de desenvolvimento precisa ser realizada à luz das realidades empíricas das comunidades para as quais são construídas. No caso brasileiro, a gama de comunidades potencialmente afetadas pela busca de implementação de um modelo nacional de TBC é extremamente ampla e diversa. A análise do caso Pataxó busca demonstrar que não é possível sujeitar povos indígenas a lógicas de desenvolvimento comunitário formuladas a partir de reflexões alheias à sua realidade. Isso implica necessariamente dizer que, para fazer avançar o modelo de TBC - seja ele teórico ou institucional - é preciso empreender uma análise amplas das experiências nacionais, considerando suas consistências e inconsistência com os modelos teóricos e institucionais. Somente à luz de tal análise, ainda não empreendida na realidade brasileira, será possível fazer emergir, de fato, novas práticas e saberes a respeito das possibilidades da gestão comunitária para o desenvolvimento de povos indígenas, comunidades quilombolas e outros povos tradicionais na sociedade brasileira.

Finalmente, é importante salientar que a análise posta em curso neste trabalho não tem qualquer relação com o anseio de invalidar, desabonar ou descredibilizar o que se chamou de o modelo TBC. Antes o contrário, pretendeu-se, aqui, prestar contribuição crítica e reflexiva à reelaboração do modelo. Considera-se que tal crítica passa pelo fato de que qualquer modelo teórico ou institucional de desenvolvimento da atividade é de natureza estrutural e como tal, para não se tornar em um modelo estéril ou encapsulante precisa necessariamente passar por cotidianas revisões críticas e adaptações contextuais para prestar sua contribuição.

De tal modo, o trabalho pretende trazer um alerta relevante, ainda que não se o considere ignorado pelos propositores do TBC, quanto à necessidade de revisão constante do modelo teórico. Essa preocupação, além de interessada relativamente à realidade indígena, se inspira fortemente em uma ambição pedagógica de reelaborar práticas de ensino do TBC no contexto acadêmico, visando que tal se reflita nas ações dos profissionais. Uma ambição deste porte está inspirada nos princípios de imbricação entre as práticas de pesquisa e de ensino, que modelam as instituições públicas de ensino superior no Brasil, e se configura em um profundo acreditar que as práticas de pesquisa devem esmerar-se tanto quanto esteja ao seu alcance em inspirar novos modos de ensinar e, obviamente, de aprender com a prática do TBC.

\section{REFERÊNCIAS}

Barreto Filho, H.T. (2004) Invenção ou Renascimento: Gênese de uma Sociedade Indígena Contemporânea no Nordeste. In: Oliveira, J.P. (Org.). A viagem da volta: etnicidade, política e reelaboração cultural no Nordeste Indígena. 2.ed. Rio de Janeiro, Brasil: Contra Capa/ LACED.

Barth, F. (1998) Grupos Étnicos e suas fronteiras. In: Poutignat, P. \& Streiff-Fenard, J. Teorias da etnicidade. Seguido de grupos étnicos e suas fronteiras de Fredrik Barth, Tradução de Elcio Fernandes. São Paulo, Brasil: UNESP.

Bartholo, R., Bursztyn, I., Fratucci, A. C., \& Assad, L. T. (2016). Turismo de base comunitária em foco. Caderno Virtual de Turismo, 16(2). DOI: http://dx.doi.org/10.18472/ cvt.16n2.2016.1344 
Castro, L. L. C., \& Pinto, R. (2013). Sustentabilidade e turismo comunitário: Caderno Virtual de Turismo, 13(2), 213-226. Disponível em: 359 (ufrj.br). Acesso 01 fev. 2021

Carvalho, M. R. G. (1977) Os Pataxó de Barra Velha: seu subsistema econômico. Dissertação de Mestrado. Programa de Pós-Graduação em Ciências Sociais, UFBA, Salvador.

Cordeiro, A. M. et al (2007) . Revisão sistemática: uma revisão narrativa. Rev. Col. Bras. Cir., Rio de Janeiro, v. 34, n. 6, p. 428-431,Dec. DOI: https://doi.org/10.1590/S010069912007000600012

Clastres, P. 2003. A sociedade contra o Estado. São Paulo, Brasil: Cosac \& Naify.

Dachary, A. C., \& Arnaiz Burne, S. M. (2009). Pueblos originarios y turismo en América Latina: La conquista continúa. Estudios y Perspectivas En Turismo, 18(1), 69-91. Disponível em: https://www.estudiosenturismo.com.ar/PDF/V18/v18n1a5a.pdf. Acesso 01 fev. 2021

Fabrino, N. H., Nascimento, E. P. do, \& Costa, H. A. (2016). Turismo de Base Comunitária: uma reflexão sobre seus conceitos e práticas. Caderno Virtual de Turismo, 16(3) DOI: http://dx.doi.org/10.18472/cvt.16n3.2016.1178

Freddy, H., Morgado, M., (2006) Turismo Comunitário: una nueva alternativa de desarrollo indígena. Revista de Antropología Iberoamericana, Ed. Electrónica Vol 1. Num. 2. MarzoJulio 2006. Pp. 249-264 . Disponível em: http://www.aibr.org/antropologia/01v02/ articulos/010202.pdf. Acesso 01 fev. 2021

Graburn, N. (1984). The evolution of tourist art. Annals of Tourism Research. Vol.11. Num.3 Pp.393-419. DOI. https://doi.org/10.1016/0160-7383(84)90029-X

Grünewald, R. A. (1999) Os 'Índios do Descobrimento': tradição e turismo/ Rodrigo de Azeredo Grünewald. Rio de janeiro: UFRJ/ MN/PPGAS, 1999. Disponível em: https://indiosnonordeste.com.br/wp-content/uploads/2012/08/TESE-SOBRE-OSPATAX\%C3\%93-BAHIA.pdf. Acesso 01 fev. 2021

Kraychete, G. (Org.). (2000). Economia dos setores populares: entre a realidade e a utopia. Petrópolis: Vozes; Rio de Janeiro: Capina; Salvador: Cese: UCSAL.

Leff, E. (2001). Saber Ambiental: sustentabilidade, racionalidade, complexidade, poder. Petrópolis, Brasil: Vozes.

MacCannel, D. (1992). Reconstructed ethnicity: tourism and cultural identity in Third World communities. In: MacCannel. Empty meeting grounds. London Routledge, p.158-171.

Maldonado, C. (2007). Fortalecendo as Redes de Turismo Comunitário - REDTURS - na América Latina. Turismo Sustentável e Desenvolvimento Local. Turim, Itália: Centro Internacional de Formação da OIT, @local.glob, 4, 08-14. Disponível em: https://www. nacionmulticultural.unam.mx/empresasindigenas/docs/2053.pdf. Acesso 01 fev. 2021

Neves, S.C. (2012). A apropriação indígena do turismo: os Pataxó de Coroa Vermelha e a expressão da tradição. Tese de Doutorado. Salvador: UFBA/PPGA. Disponível em: https://edisciplinas.usp.br/pluginfile.php/4945117/mod_resource/content/1/ AapropriaoIndgenadoTurismo_OsPataxdeCoroaVermelhaeaExpressodaTradio.pdf. Acesso 01 fev. 2021

Nuñez, T. (1963) Tourism, Tradition and Acculturation: Weekendismo in a Mexican Village. Ethnology, v. 2, n.3, p. 347-352, 1963. DOI: $10.2307 / 3772866$.

Oliveira, J.P. (Org.). (2004). A viagem da volta: etnicidade, política e reelaboração cultural no Nordeste Indígena. 2.ed. Rio de Janeiro, Brasil: Contra Capa/ LACED.

Ruiz, E., Hernández, M., Coca, A., Cantero, P., \& Del Campo, A. (2008). Turismo comunitario en Ecuador. Pasos. Revista de Turismo y Patrimonio Cultural, 6(3), 418. DOI: https:// doi.org/10.25145/j.pasos.2008.06.031 
Sachs, I. (2004). Desenvolvimento: includente, sustentavel, sustentado. Rio de Janeiro, Brasil: Garamond,

Sachs, W (ORG.) (1992). The Development Dictionary. Zed, Ingland: London.

Sánchez-Morales, J. C., Oseguera-Arias, F. E., \& Isunza-Bizuet, A. A. (2014). Turismo de base comunitaria y experiencias locales. Estudio de caso la comunidad indígena Maravilla Tenejapa, Chiapas. Ra Ximhai, 10(3), 86-101. Disponível em: http://www.revistas. unam.mx/index.php/rxm/article/view/71135. Acesso 01 fev. 2021

Singer, P. (2002) Introdução à Economia Solidária. São Paulo, Brasil: Fundação Perseu Abramo.

Skewes, J. C., Zuñiga, C. H., \& Vera, M. P. (2015). Turismo Comunitario o de base comunitaria: una experiencia alternativa de hospitalidad vivida en el mundo Mapuche. Tralcao Sur De Chile. CULTUR - Revista de Cultura e Turismo, 6(2), 73-85 Disponível em: http:// periodicos.uesc.br/index.php/cultur/article/view/285. Acesso 01 fev. 2021

Smith, V. L. (Org.) (1977). Hosts and Guests. The Anthropology of Tourism. Philadelphia: University of Pennsylvania Press.

Toren, C. (1988). Making the Present, Revealing the Past: the mutability and continuity of tradition as process. Man , New Series , Vol . 23 , No . 4, Dec. Disponível em: https:// www.jstor.org/stable/i330178. Acesso 01 fev. 2021

Van Den Berghe, P., Keyes, C. (1984) Introduction: tourism and re-created ethnicity. Annals of Tourism Research. v11 p.343-352. https://doi.org/10.1016/0160-7383(84)90026-4.

Recebido em: 08/05/2021

Aprovado em: 16/07/2021

\section{CONTRIBUIÇõES}

Sandro Campos Neves: Autoria única. 